\title{
Research on Artificial Intelligence Basic Platform and its Application in Educational Robot
}

\author{
Zhicheng Chen*, Jichun Zhao and Duoli Wang \\ Beijing Grid Fractal Dimension Technology Co., Ltd. A208, IMWay Street, Zhongguancun, Beijing, China. Post Code 100083 \\ ${ }^{*}$ Corresponding author
}

\begin{abstract}
The foundation of artificial intelligence is an important research content. This paper introduces the "Artificial Intelligence Basic Platform" project of independent research and development. The paper draws up the development contents of the artificial intelligence computing platform, formulates the concrete scheme of implementation, and implements the humanoid intelligent education robot as an application case. The work of this paper is of great significance for researchers in this field.
\end{abstract}

Keywords-artificial intelligence; computing platform; educational robot

\section{INTRODUCTION}

With the advent of the era of intelligence, artificial intelligence has become more and more widely used, but the vast majority of core technologies are occupied by the United States, Japan and European countries. Under the highly competitive global environment for high-tech technology, how does China base itself in the era of intelligence, and whether or not it has its own core intellectual property rights in artificial intelligence becomes very important. In the "New Generation Artificial Intelligence Development Plan” released by the State Council in 2017[1], the basic research of artificial intelligence is regarded as an important content. It is planned to achieve a major breakthrough in the basic theory of artificial intelligence in 2025. At present, there are already a number of universities and companies that are also engaged in research on the basic theory of artificial intelligence. For example, the predecessors of the China Artificial Intelligence Society: Prof. Xuyan TU, Yixin ZHONG, Huacan HE, Peizhuang WANG, Fuquan ZHENG, etc., put forward respectively in the basic theoretical research: coordination theory, mechanism-based artificial intelligence theory, universal logic theory[2], factor space theory, intelligent logic theory[3] and so on.

In order to promote the application of the basic theory of artificial intelligence, it is advocated by relevant experts and scholars in China, funded by science and technology companies, and independently established the basic platform for artificial intelligence[4]. The project aims to encapsulate the basic algorithms in the field of artificial intelligence, build an artificial intelligence base algorithm database, and provide external development calls for external applications, providing a unified platform for artificial intelligence applications in various fields. On the basis of introducing the research background of the project, the paper gives the research and development content of the project, formulates the specific implementation plan for the project development, and implements the humanoid education robot[5] as a typical application case.

\section{BACKGROUND OF ARTIFICIAL INTELLIGENCE ROBOT DEVELOPMENT}

According to the course of social development, it has mainly gone through three stages: the first stage is the agricultural society, the human labor tools are mainly simple sickles and gimmicks; the second stage is the industrial society, that is, the era of power locomotives, which is represented by the steam engine and machine tool; the third stage is the information society. The arrival of the Internet era has enabled us to enter the information society.

At present we have entered the fourth stage, the era of intelligence. Intelligent era requires intelligent tools. Machine substitution is an inevitable trend in some areas. Presently, the artificial intelligence and robotics industries in China are still relatively backward. The key crux of the analysis can be summarized as five words: late, few, small, slow and separate.

- Late: Compared to Germany, the United States, and Japan, China's industrial sector started late. Although it is currently a big manufacturing country, it is still not an industrial power. The overall industrial level is still far behind the developed countries.

- Few: Due to the backwardness of the overall industrial technology level, the robotic equipment currently used in China is mainly imported from abroad, resulting in China having little knowledge of key technologies in the aspects of research and development, production, manufacturing, and application of robots. The production of core components is precious few.

- Small: China's enterprises engaged in artificial intelligence and robotics are small in scale. Although there are a lot of artificial intelligence and robotics companies at present, the industry is fragmented and no scale effect has been formed, and lacks of leading enterprises.

- Slow: For advanced technologies such as artificial intelligence robots, the relative thinking transformation of governments, companies and the public is quite slow. It needs take a long time to observe and experiment to decide whether to do and how to do it, which results in the slow application of new technologies. 
- Separate: China's universities and research institutes have a large number of research projects each year. However, in general, there are more researches in the laboratories, yet fewer real applications. The production, research, and research are seriously out of line, and the research needs of universities and enterprises are separated.

Comprehensively analyze the five aspects above, we propose a solution that combines "produce, research, and apply" to put the research results of university teachers on an intelligent platform quickly, enable other developers call and reduce the threshold of research and development of artificial intelligence, and suitable for more scientific research institutes and enterprises to adopt. This is the artificial intelligence platform.

\section{CONTENT OF ARTIFICIAL INTELLIGENCE FOUNDATION PLATFORM DEVELOPMENT}

\section{A. Reasearch Objective}

The research objective of the project is: research and develop a set of "artificial intelligence platform" with independent intellectual property rights, development of corresponding artificial intelligence basic algorithm database, intelligent implementation of logical reasoning, and provision of platforms and interfaces for specific applications of artificial intelligence.

\section{B. Research Contents}

The specific content of the project study is shown in Figure I. The minimum goal is to achieve the content in the leftmost column of the figure. The highest goal is to achieve the entire content from left to right, which is specifically summarized as:

1) One platform: artificial intelligence computing platform;

2) Two bases: intelligent software research and development base and intelligent application industrial base;

3) Three systems: artificial intelligence algorithm system, intelligent programming language system, natural language understanding system;

4) Four standards: smart algorithm component standards, intelligent product interface standards, natural language understanding standards, intelligent programming language specifications;

5) Five applications: education applications for major in intelligence, intelligent machine control applications, intelligent decision-making translation applications, intelligent product development applications, and network intelligence computing applications.

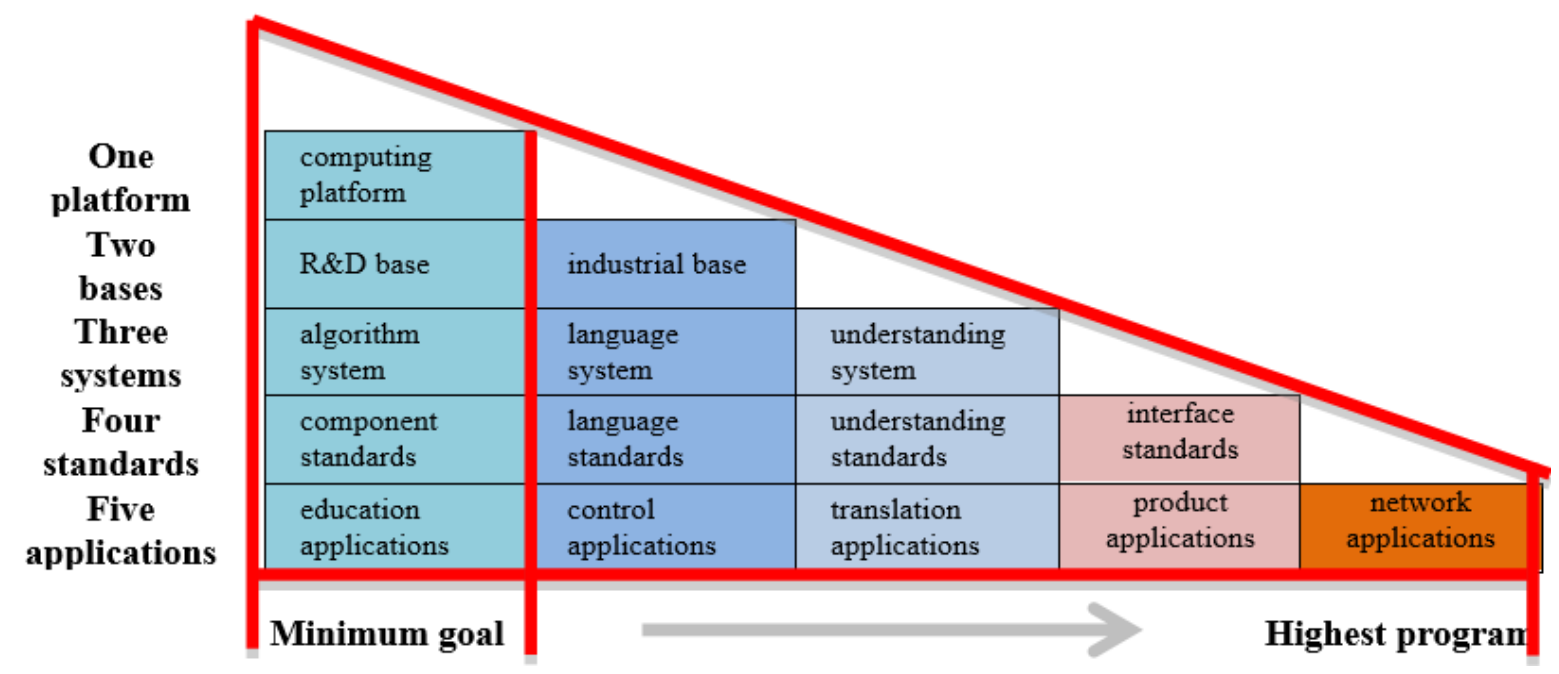

FIGURE I. RESEARCH CONTENT OF THE PLATFORM

\section{Core Products}

According to the existing basic theory of artificial intelligence and market research, the research and development of the core products are divided into three categories.

\section{1) Artificial intelligence algorithm system:}

The system integrates the existing artificial intelligence algorithms, provides external interfaces, internally implements corresponding classic algorithms and some advanced algorithms, and provides algorithms for the research and service of artificial intelligence education and intelligent systems in universities.
2) Intelligent control programming system:

Based on the characteristics of intelligent robot, an intelligent programming platform is developed to provide a new, convenient and rapid development platform for enterprise programmers in the field of automation and intelligence. Its typical application is programming control in the robot development process, which could fomulate "interface specification and intelligent programming language standard for application programming in intelligent fields.”

\section{3) Intelligent language translation system:}

In response to the increasing demand for internationalization of the current society, a "multilingual translation engine” has been developed. Through this engine, 
different languages can be translated on it dynamically, quickly and in real time. This engine implements obstacles across multiple languages and has a wide range of applications in numerous conditions.

\section{Project Features and Innovation Points}

The features and innovations of the project are mainly reflected in:

1) New artificial intelligence basic theoretical system:

Based on the research achievements of artificial intelligence of Chinese scholars, artificial intelligent algorithms of many well-known experts are integrated to build a unified artificial intelligence basic platform;

2) New intelligent software platform:

The project establishes an intelligent software architecture based on "smart knowledge base and logic inference engine", which can realize the intelligent program loading, operation, management and rapid calculation on this architecture;

\section{3) New intelligent software programming model:}

The project develops a set of software programming languages for the intelligent field, provides an intelligent programming environment, a fast programming function interface. It greatly simplifies complex and sophisticated artificial intelligence algorithms to the extent that normal software engineer could retrieval;

4) New heterogeneous language understanding system:

Based on speech recognition and natural language understanding technologies, the project plans to develop an "intelligent language translation engine" that enables mutual understanding of multiple languages and automatic and rapid translation;

5) Has full independent intellectual property rights:

The project is entirely based on the research results of our country's experts. The main experts and technical personnel are from relevant domestic universities and well-known enterprises. All theories and products have completely independent intellectual property rights.

\section{RESEARCH AND DEVELOPMENT IMPLEMENTATION PLAN}

The content of project development could be divided into three levels: basic platform, professional algorithm, and application system, as shown in Figure II.

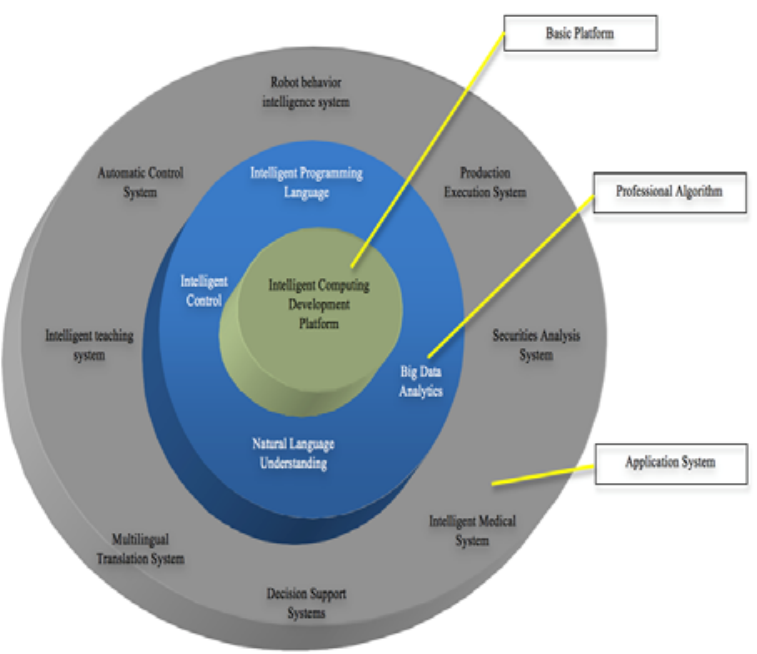

FIGURE II. THREE LEVELS OF PLATFORM DEVELOPMENT

According to the three levels of design, the specific R\&D steps for the project are: first establish an artificial intelligence basic platform, secondly develop professional algorithms, then develop application systems, and finally perform comprehensive integration, as shown in Table I.

TABLE I. IMPLEMENTATION PROCEDURE

\begin{tabular}{|c|c|c|}
\hline Level & Procedure & Development Content \\
\hline $\begin{array}{c}\text { Basic } \\
\text { platform }\end{array}$ & $\begin{array}{l}\text { 1. Build an intelligent } \\
\text { computing platform }\end{array}$ & $\begin{array}{l}\text { Establish AI basic } \\
\text { platform, develop } \\
\text { logical reasoning } \\
\text { system, and carry out } \\
\text { artificial intelligence } \\
\text { technology learning. }\end{array}$ \\
\hline $\begin{array}{c}\text { Professional } \\
\text { algorithm }\end{array}$ & $\begin{array}{l}\text { 2. Natural language } \\
\text { understanding } \\
\text { 3. Intelligent control } \\
\text { algorithm } \\
\text { 4. Intelligent programming } \\
\text { language } \\
\text { 5. Big data analytics }\end{array}$ & $\begin{array}{l}\text { Develop professional } \\
\text { algorithms in the field } \\
\text { of artificial } \\
\text { intelligence, design } \\
\text { interfaces, and } \\
\text { implement } \\
\text { corresponding } \\
\text { algorithms. }\end{array}$ \\
\hline $\begin{array}{l}\text { Application } \\
\text { system }\end{array}$ & $\begin{array}{l}\text { 6. Intelligent teaching system } \\
\text { 7. Robot behavior system } \\
\text { 8. Automatic control system } \\
\text { 9. Multilingual translation } \\
\text { system } \\
\text { 10. Decision support System } \\
\text { 11. Intelligent medical system } \\
\text { 12. Securities analysis system } \\
\text { 13. Production execute } \\
\text { system }\end{array}$ & $\begin{array}{c}\text { Analyzes and } \\
\text { summarizes typical } \\
\text { application fields, } \\
\text { establishes intelligent } \\
\text { knowledge base, } \\
\text { algorithm library, and } \\
\text { scenario library, and } \\
\text { designs and develops } \\
\text { and implements its } \\
\text { applications. }\end{array}$ \\
\hline $\begin{array}{l}\text { Platform } \\
\text { integration }\end{array}$ & $\begin{array}{l}\text { 14. Artificial intelligence } \\
\text { computing platform } \\
\text { integration }\end{array}$ & $\begin{array}{l}\text { Integrate all functional } \\
\text { modules of the basic } \\
\text { platform, professional } \\
\text { algorithms, and } \\
\text { application systems } \\
\text { according to the } \\
\text { designed interface. }\end{array}$ \\
\hline
\end{tabular}




\section{ApPliCATION OF PlatForm In EDUCATIONAL RoBOT}

\section{A. System Design of Intelligent Education Robot}

Based on an artificial intelligence platform, a robot system for education was developed and designed for "humanoid robots." The entire robot system is designed as a three-tier architecture: a robot sensing layer, a cloud platform processing layer, and a robot operation application layer, as shown in Figure III.

1) Robot perception layer:

Solve the "body" of the robot's hardware and software function design, mechanical structure design, sensor detection and perception of the environment, as well as some localized voice features and other issues.

\section{2) Cloud platform processing layer:}

Provides artificial intelligence algorithm database and corresponding interface, mainly including voice recognition and dialogue, image processing, natural language understanding, search and other functions.

\section{3) Robot application layer:}

A service robot is constructed and configured for a common scenario and a selection library is provided to provide mobile phone or PC application operating software.

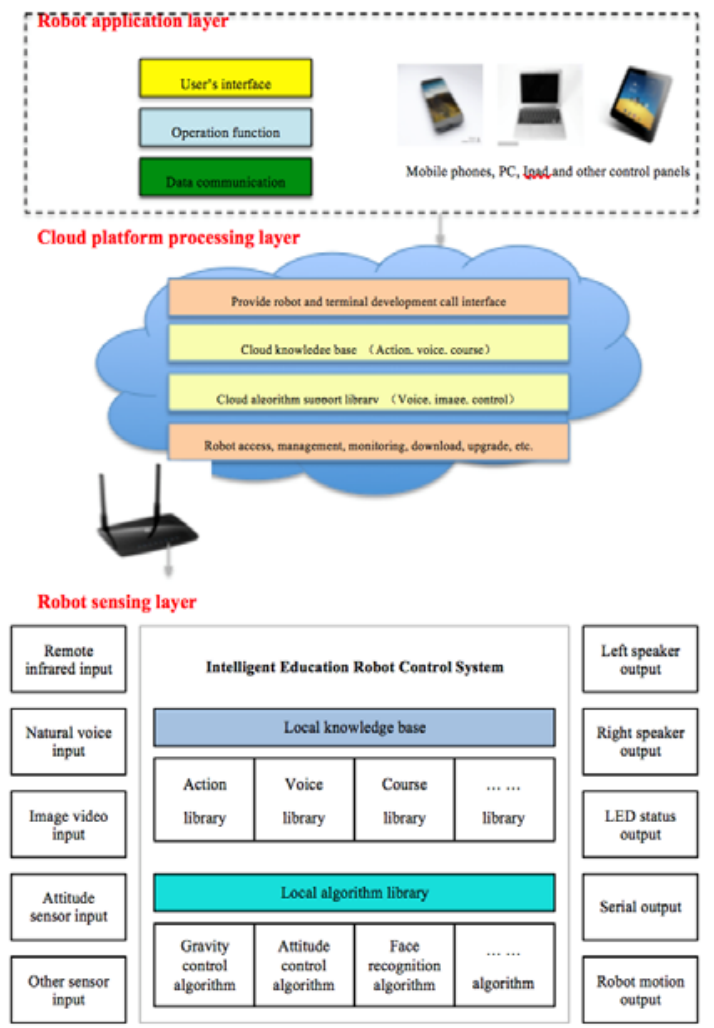

FIGURE III. INTELLIGENT EDUCATION ROBOT SYSTEM DESIGN

\section{B. Robot's Function Module}

The intelligent education robot developed on the artificial intelligence platform adopts a modular approach to hardware and software design for assembly on demand and on-demand calls. The main modules are as follows:

1) Main controller module

2) Head designing module

3) Hand designing module

4) Chest designing module

5) Arm designing module

6) Leg designing module

7) Obstacle avoidance control module

8) Speech recognition, autonomous answering module

9) Face recognition module

10) Scene recognition, environmental perception module

\section{Robot Knowledge, Motion Experience Library}

Based on the teaching content of primary and secondary schools, the language, mathematics, physics, chemistry, biology, and encyclopedia knowledge bases of all grades were designed. At the same time, a database of songs, stories, storytelling and other speech data was designed, as shown in Figure IV.

In the action library of intelligent education robots, the human-computer interaction operation experience is increased. The main design is: basic action library, individual action library, dance action library, gymnastics action library, Sinology action library, and expansion action library.

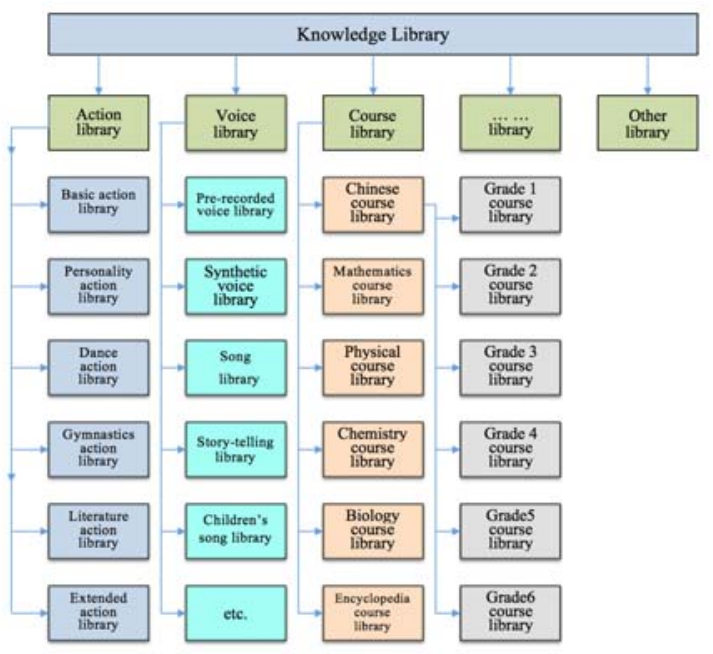

FIGURE IV. EDUCATIONAL ROBOT’S KNOWLEDGE LIBRARY

The intelligent education robots developed based on artificial intelligence platform have been used in many schools and universities now.

\section{SUMMARY}

Artificial intelligence technology is rapidly developing. In order to rapidly develop artificial intelligence applications, the paper proposes to develop an artificial intelligence basic platform and implement it in a certain field. At present, it has 
been applied in intelligent control and intelligent education robots. With the expansion of specific needs in the future, the platform will increase the development of more types of algorithms, and provide more and more applications.

\section{ACKNOWLEDGMENT}

This paper is supported by the innovation fund (Project No.CXJJ0027) of Fengtai District, Beijing, China.

\section{REFERENCES}

[1] The State Council of the people's Republic of China.The new generation of AI development plan. Beijing: State Council, July 2017.

[2] Huacan HE,Hua WANG, Yonhhuai LIU, et al. Principle of universallogics. Beijing: Science press, 2006.

[3] Fuquan ZHENG. Intelligent logic. Lanzhou: Lanzhou university press, 2001.

[4] Zhicheng CHEN. China's independent innovation research and development project: AI computing platform [online], http://www. iot101.com/editor/2016-01-21/1795.html, 2016.

[5] Jichun ZHAO, Zhicheng CHEN. A walking control method based on genetic algorithm for humanoid biped robot, [Patent: CN201610317278.0], 2016. 